Vietnam Journal of Mechanics, VAST, Vol.39, No. 2 (2017), pp. 149-164

DOI:10.15625/0866-7136/8745

\title{
DETERMINATION OF DYNAMIC IMPACT FACTOR FOR CONTINUOUS GIRDER BRIDGE DUE TO VEHICLE BRAKING FORCE BY FINITE ELEMENT METHOD AND EXPERIMENTAL
}

\author{
Nguyen Xuan Toan ${ }^{1, *}$, Tran Van Duc ${ }^{2}$ \\ ${ }^{1}$ Da Nang University of Science and Technology, Da Nang University, Vietnam \\ ${ }^{2}$ International School, Duy Tan University, Da Nang City, Vietnam \\ *E-mail: nguyenxuantoan2007@gmail.com \\ Received September 29, 2016
}

\begin{abstract}
In this study, the finite element method (FEM) is used to investigate the dynamic response of continuous girder bridge due to moving three-axle vehicle . Vertical reaction forces of axles that change with time make bending vibration of girder significantly increase. The braking in the first span is able to create response in other spans. In addition, the dynamic impact factors are investigated by both FEM and experiment for Hoa Xuan bridge. The results of this study provide an improved understanding of the bridge dynamic behavior and can be used as additional references for bridge codes by practicing engineers.
\end{abstract}

Keywords: Dynamic impact factor, braking effects, FEM, experiment, three-axle vehicle, Hoa Xuan Bridge.

\section{INTRODUCTION}

Dynamic interactions between vehicle and bridge were initially interested in railway engineering, they rapidly attracted attention of highway engineering. The initial researchers had studied the response of bridges subjected to vehicles moving since the 50 s of the 19th century. Frýba [1] also provided a fundamental study of girder due to mass roll on the train rails considering the braking effects, and investigated the quasistatic distribution of braking as well. Kishan and Trail-Nash [2] studied the dynamic response of highway bridges due to vehicle loading considering braking force, and the resulting impact factors may be larger than those adopted in the current design code. Gupta and Trail-Nash [3] investigated the dynamic behavior of bridge model with single span uniform girder considering the road surface irregularities and vehicle braking force. Mulcahy [4] carried out method for analysis of dynamic interaction between single span

(C) 2017 Vietnam Academy of Science and Technology 
bridges and a three-axle tractor-trailer vehicle considering vehicle acceleration, braking effects and roughness of the road surface. Yang and $\mathrm{Wu}$ [5] applied and a developed numerical method to investigate the dynamic behavior of a bridge when vehicle was decelerating. Hu and Han [6] presented a nonlinear dynamic model of four-wheel-steering vehicles considering the braking force, as well as the air drag and wind effect. Law and Zhu [7] studied the dynamic behavior of continuous three spans under moving vehicle considering the roughness of the road surface. Ju and Lin [8] used the FEM to calculate the vertical vibration of girders caused moving vehicle due to the braking force with simple model. González et al. [9] presented an algorithm based on first-order Tikhonov regularization and dynamic programming for the identification of moving vehicle forces on a bridge. Zhisong and Nasim [10] based on results of routine bridge weight-in-motion, the simulation approach is developed and proposed to predict bridge safety and integrity if heavy trucks experience emergency braking on the bridge. Deng et al. [11] studied the dynamic impact factors for shear and bending moment of both simply supported and continuous bridges due to vehicle loading by numerical simulations. However, most of the previous research on dynamic interaction between the vehicle and simply supported bridge, very few studies have focused on the multi-span continuous girder bridge considering braking effects. Additionally, the field test is needed in order to obtain a clearer understanding of the relationship between dynamic interaction for bridge types and vehicle models.

This paper investigates the dynamic response of continuous girder bridge subjected to dynamic wheel loads by FEM and experiment. The vibration of the multi-span continuous girder bridge was analyzed with various vehicle speeds considering the braking effects to assess the amount of interaction between the vehicle and multi-span continuous girder bridge.

The main objective of the test is to validate the calculation procedure for determining the Dynamic Impact Factor (DIF) of the continuous girder bridge under dynamic wheel loads considering the vehicle speed and braking effects. There are many definitions for DIF or (1+IM) (AASHTO [12]), DIF in this paper is taken as the ratio of dynamic and static responses

$$
(1+I M)=D I F=\frac{D_{\text {dynamic }}}{D_{\text {static }}}
$$

where $D_{\text {dynamic }}$ is the absolute maximum dynamic deflection response at any point and $D_{\text {static }}$ is the maximum static response obtained from the filtered dynamic response. An example of bridge response for a vehicle moving on the highway bridge is shown in Fig. 1.

The movement of vehicle based on a four-mass model, including the mass of the entire vehicle and three axles, rotational inertia of the chassis, the damping and the suspension stiffness, spring and tires. Numerical analysis results were compared with the experimental testing results performed on the Hoa Xuan bridge in Danang city, Vietnam. 


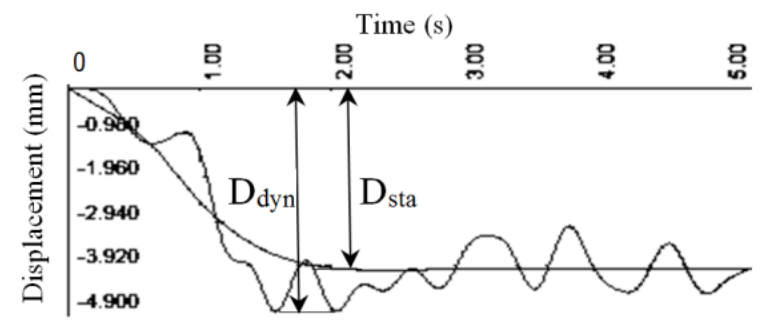

Fig. 1. Dynamic and static displacement under a vehicle moving

\section{FINITE ELEMENT METHOD ANALYSIS}

\subsection{Computational models and assumptions}

The diagram of a three-axle vehicle moving on the Hoa Xuan bridge in Danang city is described as in Fig. 2. The dynamic interaction model between a three-axle vehicle and a girder element considering vehicle braking force is described as in Fig. 3.

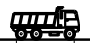

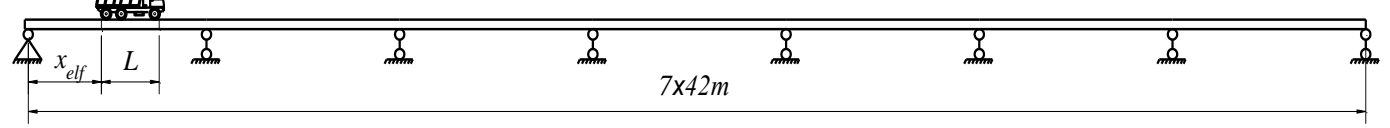

Fig. 2. The model of a three-axle vehicle moving on the Hoa Xuan bridge

in which

$x_{i}=\left\{\begin{array}{ll}v_{i} \cdot\left(t-t_{i}\right)-x_{e l f} ; & \text { if } t_{i} \leq t \leq t_{b i} \\ v_{i} \cdot\left(t_{b i}-t_{i}\right)+\left[\frac{a_{i} \cdot\left(t-t_{b i}\right)}{2}+v_{i}\right] \cdot\left(t-t_{b i}\right)-x_{e l f} ; & \text { if } t_{b i}<t \leq t_{e i}\end{array}\right.$ and $0 \leq x_{i} \leq L ;$

$x_{i}$ - the coordinate of the $i^{t h}$ axes of the vehicle at time $t(i=1,2,3)$;

$t$ - time variation;

$a_{i}$ - the acceleration of the $i^{\text {th }}$ axle when a brake is used $\left(a_{i}<0\right)$;

$L$ - the length of the girder elements;

$x_{0}$ - the coordinate of the center of mass $m$ at time $t$;

$x_{e l f}$ - the distance between the left side of the bridge and the left side of the girder element;

$v_{i}$ - the velocity of the $i^{\text {th }}$ axle before a brake is used;

$t_{i}$ - the point of time when the $i^{\text {th }}$ axle begins entering the bridge;

$t_{b i}$ - the point of time when a brake on the $i^{t h}$ axle is used;

$t_{e i}$ - the point of time when the $i^{\text {th }}$ axle stops;

$P$ is the stimulation force caused by the eccentric mass of the engine;

$m$ - the mass of vehicle body, excluding the mass of the axles;

$s$ - the distance of vehicle moving from left end of bridge;

$u$ - vertical displacement of the chassis at centre of mass $m$;

$\varphi$ - the rotation angle of the chassis;

$\bar{u}_{1}, \bar{u}_{2}, \bar{u}_{3}$ - the vertical displacement of chassis at the three axles;

$u_{1}, u_{2}, u_{3}$ - the vertical displacement of the three axles;

$y_{s 1}, y_{s 2}, y_{s 3}$ - the relative displacement between the chassis and the three axles; 
$y_{t 1}, y_{t 2}, y_{t 3}$ - the relative displacement between the girder element and the three axles; $h_{1}, h_{2}, h_{3}$ - the height from the centre of girder element to centre of mass $m_{1}, m_{2}, m_{3}$ respectively;

$T_{t 1}, T_{t 2}, T_{t 3}$ - the friction forces between tire and bridge surface at the three axles.

$m_{1}, m_{2}, m_{3}$ - the mass of the $1^{\text {st }}, 2^{\text {nd }}, 3^{\text {nd }}$ axle respectively;

$w_{1}, w_{2}, w_{3}$ - the displacement of girder element at $1^{\text {st }}, 2^{\text {nd }}, 3^{\text {nd }}$ axle respectively;

$k_{s 1}, k_{s 2}, k_{s 3}, d_{s 1}, d_{s 2}, d_{s 3}$ - the stiffness and the damping of the three axles;

$k_{t 1}, k_{t 2}, k_{t 3}, d_{t 1}, d_{t 2}, d_{t 3}$ - the stiffness and the damping of the three tires;

Inertial forces, damping forces, elastic forces, stimulating forces and braking forces affecting the system are described as Fig. 3.

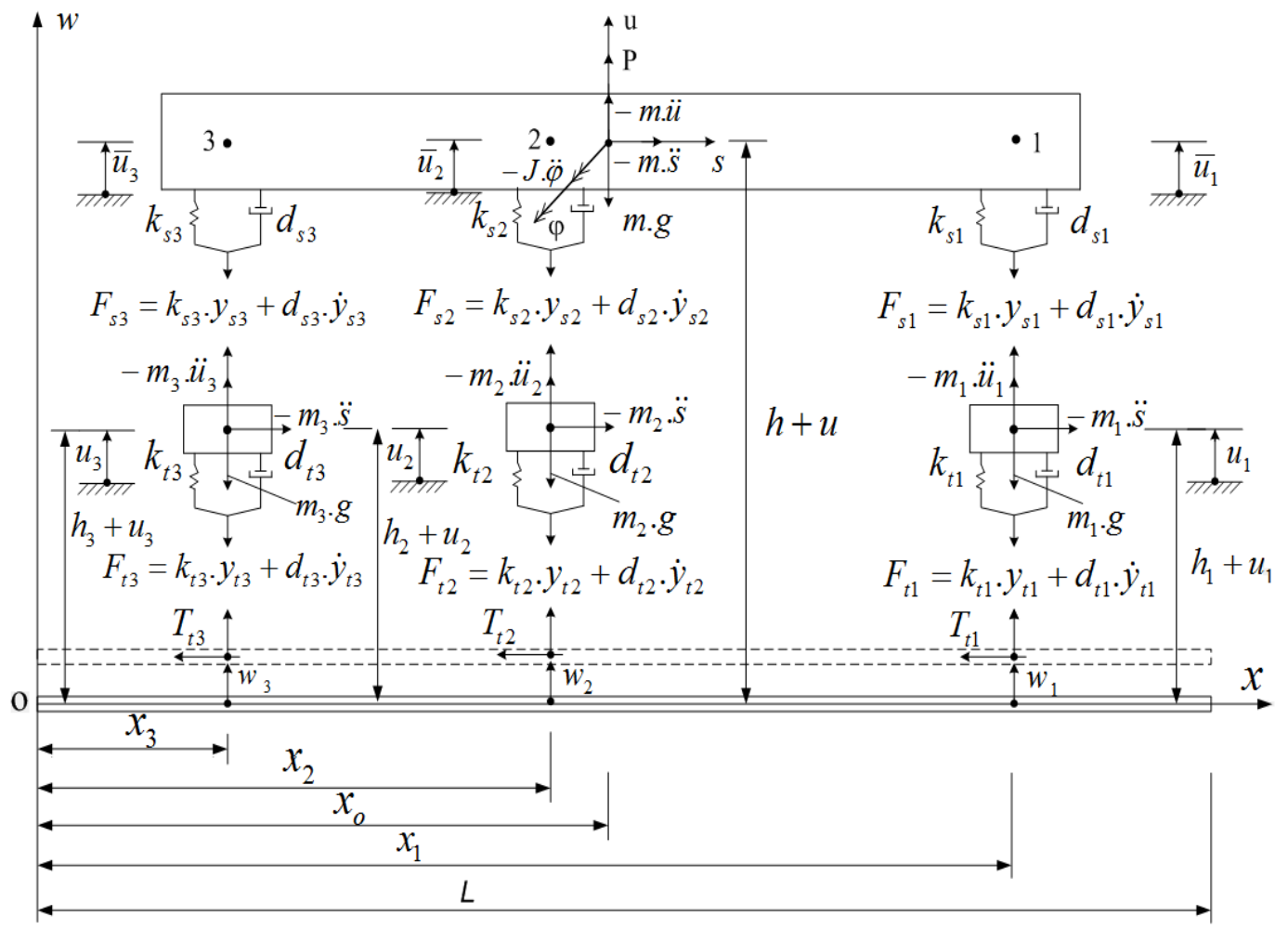

Fig. 3. The analytical model three-axle vehicle moving on girder element

The following assumptions are adopted:

The mass of the entire vehicle, excluding the mass of the axles is transferred to the center of masses of the system. It is equivalent to the mass $\mathrm{m}$ and the rotational inertia $J$.

The mass of the $1^{\text {st }}$ axle is $m_{1}$, which is regarded as a mass point at the center of the corresponding axle. This is the same case for the masses of $2^{\text {nd }}$ and $3^{\text {rd }}$ axle are $m_{2}$ and $m_{3}$.

The chassis is hypothesised to be absolutely hard and undistorted when moving.

The materials of a girder are in the linear elastic stage. The bridge surface is flat, and has the homogeneous friction coefficient over the entire bridge surface. 
Braking forces of the axles of vehicle are assumed to occur simultaneously. The direction of the forces between bridge surface and tires are assumed to be in the opposite direction of the movement of a vehicle as shown in Fig. 3.

From this assumption, the friction forces between bridge surface and tires make the vehicle decelerate gradually and cause inertia forces: $-m_{1} \ddot{s},-m_{2} \ddot{s},-m_{3} \ddot{s}$.

The most dangerous case is when a brake is suddenly applied. In this case, $T_{t 1}, T_{t 2}$ and $T_{t 3}$ are assumed to be directly proportional to loaded weight of vehicle

$$
T_{t 1}+T_{t 2}+T_{t 3}=\left(m+m_{1}+m_{2}+m_{3}\right) \cdot g \cdot \tau,
$$

where $\tau$ - the coefficient of friction between bridge surface and tires; $g$ - the acceleration of gravity.

\subsection{Bending vibration of girder elements due to braking force applied to a three-axle vehicle}

Basing on the above calculation model and assumptions, the system of masses $m$, $m_{1}, m_{2}, m_{3}$, inertia forces, damping forces, elastic forces, stimulating force and braking forces are factors under analysis. In this case, braking forces are converted to friction forces $T_{t 1}, T_{t 2}, T_{t 3}$ as shown in Fig. 3.

Using d'Alembert's principle and considering the equilibrium of each mass $m, m_{1}$, $m_{2}, m_{3}$ on the vertical axis and the longitudinal axis system, we get following equations

$$
\left\{\begin{array}{l}
P-m \ddot{u}-\sum_{i=1}^{n} F_{s i}-m g=0 \\
F_{s i}-F_{t i}-m_{i} \cdot \ddot{u}_{i}-m_{i} g=0 \\
\sum_{i=1}^{n} T_{t i}+\left(m+\sum_{i=1}^{n} m_{i}\right) \cdot \ddot{s}=0
\end{array}\right.
$$

with $i$ is number of axles $(i=1,2,3)$.

Considering the equilibrium equation of the system with the $\mathrm{O}$ point in Fig. 3 to get equations

$$
\begin{array}{r}
(P-m \cdot \ddot{u}-m \cdot g) \cdot x_{o}+m \cdot \ddot{s} \cdot(h+u)-J \cdot \ddot{\varphi}-\sum_{i=1}^{n}\left(m_{i} \cdot \ddot{u}_{i}+m_{i} \cdot g\right) \cdot x_{i} \\
+\sum_{i=1}^{n} m_{i} \cdot \ddot{s} \cdot\left(h_{i}+u_{i}\right)+\sum_{i=1}^{n}\left(T_{t i} \cdot w_{i}-F_{t i} \cdot x_{i}\right)=0,
\end{array}
$$

where

$$
\begin{aligned}
& F_{s i}=k_{s i} y_{s i}+d_{s i} \dot{y}_{s i} ; \quad F_{t i}=k_{t i} y_{t i}+d_{t i} \dot{y}_{t i} ; \quad \bar{u}_{i}=u+\left(x_{i}-x_{o}\right) \operatorname{tg} \varphi \approx u+\left(x_{i}-x_{o}\right) \varphi ; \\
& y_{s i}=\bar{u}_{i}-u_{i} \approx u+\left(x_{i}-x_{o}\right) \varphi-u_{i} ; \quad y_{t i}=u_{i}-w_{i} .
\end{aligned}
$$


Substituting Eq. (6) in to Eqs. (4) and (5), and combining Eqs. (3), (4) and (5), we obtained the following set of equations

$$
\begin{aligned}
& J \cdot \ddot{\varphi}+\sum_{i=1}^{n} d_{s i}\left(x_{i}-x_{o}\right)^{2} \cdot \dot{\varphi}+\sum_{i=1}^{n} d_{s i}\left(x_{i}-x_{o}\right) \cdot \dot{u}-\sum_{i=1}^{n} d_{s i}\left(x_{i}-x_{o}\right) \cdot \dot{u}_{i}+\sum_{i=1}^{n} k_{s i}\left(x_{i}-x_{o}\right)^{2} \cdot \varphi \\
& \quad+\left[\sum_{i=1}^{n} k_{s i}\left(x_{i}-x_{0}\right)-m \cdot \ddot{s}\right] \cdot u-\sum_{i=1}^{n}\left[k_{s i}\left(x_{i}-x_{o}\right)+m_{i} \cdot \ddot{s}\right] \cdot u_{i}-\sum_{i=1}^{n} T_{t i} \cdot w_{i}-\left(m \cdot h+\sum_{i=1}^{n} m_{i} \cdot h_{i}\right) \cdot \ddot{s}=0, \\
& m \cdot \ddot{u}+\sum_{i=1}^{n} d_{s i}\left(x_{i}-x_{o}\right) \cdot \dot{\varphi}+\sum_{i=1}^{n} d_{s i} \cdot \dot{u}-\sum_{i=1}^{n} d_{s i} \cdot \dot{u}_{i}+\sum_{i=1}^{n} k_{s i}\left(x_{i}-x_{o}\right) \cdot \varphi+\sum_{i=1}^{n} k_{s i} \cdot u-\sum_{i=1}^{n} k_{s i} \cdot u_{i}-P+m \cdot g=0, \\
& m_{i} \cdot \ddot{u}_{i}-d_{s i}\left(x_{i}-x_{o}\right) \cdot \dot{\varphi}-d_{s i} \cdot \dot{u}+\left(d_{s i}+d_{t i}\right) \cdot \dot{u}_{i}-k_{s i}\left(x_{i}-x_{o}\right) \cdot \varphi-k_{s i} \cdot u \\
& \quad+\left(k_{s i}+k_{t i}\right) \cdot u_{i}-d_{t i} \cdot \dot{w}_{i}-k_{t i} \cdot w_{i}+m_{i} \cdot g=0 \\
& \ddot{s}=-g \cdot \tau .
\end{aligned}
$$

According to Ray and Joseph [13], the differential equation of motion for the flexure vibration of damped girder due to uniform loading $p(x, t)$ can be written as follow

$$
E J_{d} \cdot\left(\frac{\partial^{4} w}{\partial x^{4}}+\theta \cdot \frac{\partial^{5} w}{\partial x^{4} \cdot \partial t}\right)+\rho F_{d} \cdot \frac{\partial^{2} w}{\partial t^{2}}+\beta \cdot \frac{\partial w}{\partial t}=\sum_{i=1}^{n} p_{i}(x, t),
$$

where

$$
\begin{aligned}
p_{i}(x, t)= & \xi\left(x_{i}\right) \cdot F_{t i} \cdot \delta\left(x-x_{i}\right)=\xi\left(x_{i}\right) \cdot\left[-m_{i} \cdot \ddot{u}_{i}+d_{s i}\left(x_{i}-x_{o}\right) \cdot \dot{\varphi}+d_{s i} \cdot \dot{u}-d_{s i} \cdot \dot{u}_{i}\right. \\
& \left.+k_{s i}\left(x_{i}-x_{o}\right) \cdot \varphi+k_{s i} \cdot u-k_{s i} \cdot u_{i}-m_{i} \cdot g\right] \cdot \delta\left(x-x_{i}\right)
\end{aligned}
$$

with

$\xi\left(x_{i}\right)=\left\{\begin{array}{ll}1, & \text { if } 0 \leq x_{i} \leq L \\ 0, & \text { if } x_{i}<0 \text { and } x_{i}>L\end{array}\right.$ is the logic control signal function;

$\delta \cdot\left(x-x_{i}\right)$ is the Dirac delta function; $x_{i}$ is determined by the Eq. (2);

$w$ - deflection of the girder element,

$F_{d}$ - the cross-sectional area of the girder,

$J_{d}$ - the girder section's inertial moment of area,

$E$ - the Young's modulus,

$E J_{d}$ - the flexural rigidity of girder element,

$\rho F_{d}$ - the mass of girder per unit length,

$\theta$ and $\beta$ - the coefficient of internal friction and external friction.

The Galerkin method and Green theory are applied to Eqs. (7), (8), (9) transform into matrix form, and the differential equations of girder element can be written in a matrix form as follow

$$
\left[M_{e}\right] \cdot\{\ddot{q}\}+\left[C_{e}\right] \cdot\{\dot{q}\}+\left[K_{e}\right] \cdot\{q\}=\left\{f_{e}\right\} .
$$


$\{\ddot{q}\},\{\dot{q}\},\{q\},\left\{f_{e}\right\}$ - the complex acceleration vector, complex velocity vector, complex displacement vector, complex forces vector, respectively

$$
\{\ddot{q}\}=\left\{\begin{array}{c}
\ddot{w}_{e} \\
\ddot{z}
\end{array}\right\} ;\{\dot{q}\}=\left\{\begin{array}{c}
\dot{w}_{e} \\
\dot{z}
\end{array}\right\} ;\{q\}=\left\{\begin{array}{c}
w_{e} \\
z
\end{array}\right\} ;\left\{f_{e}\right\}=\left\{\begin{array}{l}
f_{w} \\
f_{z}
\end{array}\right\} ;\left\{w_{e}\right\}=\left\{\begin{array}{c}
u_{x 1} \\
w_{y 1} \\
\varphi_{1} \\
u_{x 2} \\
w_{y 2} \\
\varphi_{2}
\end{array}\right\} ;\{z\}=\left\{\begin{array}{c}
\varphi \\
u \\
u_{1} \\
\vdots \\
u_{n}
\end{array}\right\} ;
$$

where $u_{x 1}, w_{y 1}, \varphi_{1}$ - the axial displacement, flexural deflection and rotation angle of the left end of element, respectively; $u_{x 2}, w_{y 2}, \varphi_{2}$ - the axial displacement, flexural deflection and rotation angle of the right end of element, respectively; $\left[M_{e}\right],\left[C_{e}\right]$ and $\left[K_{e}\right]$ - the mass matrix, damping matrix and stiffness matrix, respectively.

$$
\left[M_{e}\right]=\left[\begin{array}{ll}
M_{w w} & M_{w z} \\
M_{z w} & M_{z z}
\end{array}\right] ;\left[C_{e}\right]=\left[\begin{array}{ll}
C_{w w} & C_{w z} \\
C_{z w} & C_{z z}
\end{array}\right] ;\left[K_{e}\right]=\left[\begin{array}{cc}
K_{w w} & K_{w z} \\
K_{z w} & K_{z z}
\end{array}\right]
$$

Where $\left[M_{w w}\right],\left[C_{w w}\right]$ and $\left[K_{w w}\right]$ - mass, damping and stiffness matrices of the girder elements, respectively. They can be found in Zienkiewicz and Taylor [14]. $M_{w z}, M_{z w}$, $M_{z z}, C_{w z}, C_{z w}, C_{z z}, K_{w z}, K_{z w}, K_{z z}$ are mass, damping and stiffness matrices of interaction between beam element and vehicle subjected to moving loads which can be found in previous study of Toan and Duc [15-19].

\subsection{Apply the FEM to analyse the dynamic vibration of the Hoa Xuan bridge}

The Hoa Xuan Bridge is a 7-span continuous concrete girder bridge with the dynamic structural model is shown in Fig. 2, and the FEM model of bridge is shown in Fig. 4. The cross section of the concrete girder bridge and position of truck is shown in Fig. 5. The three-axle vehicle used in the numerical simulation is ASIA dumper truck as shown in Fig. 6. Applying the algorithm of the FEM from Zienkiewicz and Taylor [14], differential equations that arise from vibrating systems can be stated as

$$
[M] \cdot\{\ddot{Q}\}+[C] \cdot\{\dot{Q}\}+[K] \cdot\{Q\}=\{F\},
$$

where $[M],[C],[K]$ - mass matrix, damper matrix, and stiffness matrix of the system; $\{\ddot{Q}\},\{\dot{Q}\},\{Q\},\{F\}$ - acceleration vector, the velocity vector, the deflection vector, and the force vector of the system.

Eq. (14) was computed by the Runge-Kutta-Merson method. The numerical values of the parameters were used in the computer simulation and the field test as follows: The parameters of concrete girder: $E=3230769230\left(\mathrm{~kg} / \mathrm{m}^{2}\right) ; J_{d}=0.6879\left(\mathrm{~m}^{4}\right) ; F_{d}=1.3776$ $\left(\mathrm{m}^{2}\right) ; \rho F_{d}=3800(\mathrm{~kg} / \mathrm{m}) ; \theta=0.027 ; \beta=0.01 ; \tau=0.25 ; g=9.81\left(\mathrm{~m} / \mathrm{s}^{2}\right)$.

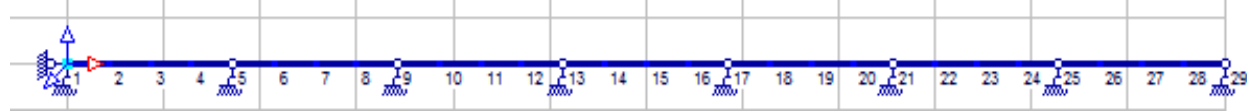

Fig. 4. The FEM model of the Hoa Xuan bridge 


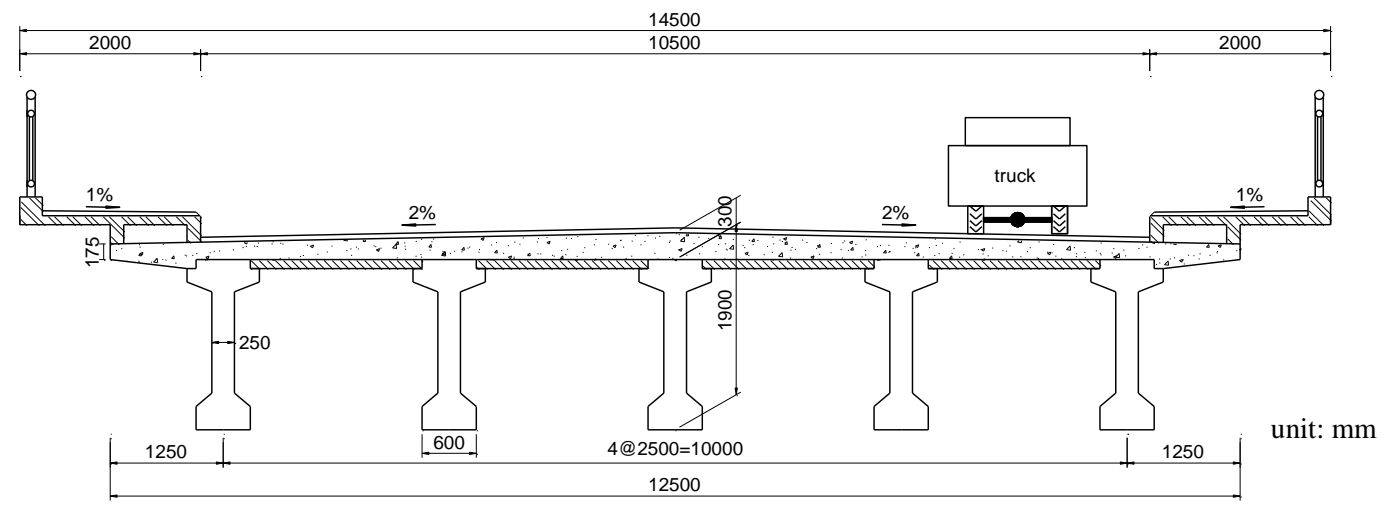

Fig. 5. Cross section of the concrete girder bridge with loading position of the truck

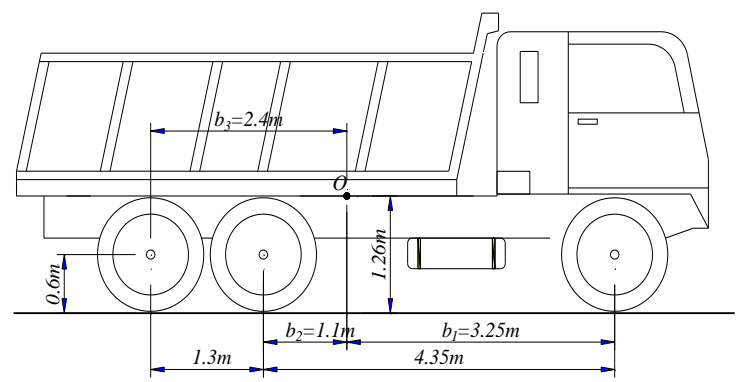

Fig. 6. The vehicle dimensional parameters

The three-axle vehicle parameters: $m=14060(\mathrm{~kg}) ; m_{1}=60(\mathrm{~kg}) ; m_{2}=110(\mathrm{~kg})$; $m_{3}=110(\mathrm{~kg}) ; P=0 ; b_{1}=3.25(\mathrm{~m}) ; b_{2}=1.10(\mathrm{~m}) ; b_{3}=2.4(\mathrm{~m}) ; h=1.26(\mathrm{~m}) ; h_{1}=h_{2}=$ $h_{3}=0.6(\mathrm{~m}) ; k_{1 s}=1.200 .000(\mathrm{~N} / \mathrm{m}) ; k_{1 t}=1.600 .000(\mathrm{~N} / \mathrm{m}) ; k_{2 s}=k_{3 s}=2.600 .000(\mathrm{~N} / \mathrm{m}) ;$ $k_{2 t}=k_{3 t}=3.200 .000(\mathrm{~N} / \mathrm{m}) ; d_{1 s}=7344(\mathrm{~N} . \mathrm{s} / \mathrm{m}) ; d_{1 t}=3670(\mathrm{~T} . \mathrm{s} / \mathrm{m}) ; d_{2 s}=d_{3 s}=4000$ (T.s $/ \mathrm{m}) ; d_{2 t}=d_{3 t}=8000$ (N.s $\left./ \mathrm{m}\right)$.

The $(1+\mathrm{IM})$ or DIFs evaluate at node $2,3,4,6,7,8,10,11$ in terms of vertical deflections for vehicle speeds of $10-50 \mathrm{~km} / \mathrm{h}$ with sudden braking are shown in Figs. 7-11.

Fig. 7 shows the DIF variations in term of vertical deflections at $10 \mathrm{~km} / \mathrm{h}$ vehicle speed with the consideration of the effect of braking. The maximum of DIF is 1.36. The DIFs increase with braking effect vary from $0 \%$ to $16.23 \%$, and the average increment of the DIFs reach $10.40 \%$ with braking effect.

Fig. 8 shows variation of DIF in terms of vertical deflections at $20 \mathrm{~km} / \mathrm{h}$ vehicle speed considering braking, the maximum of DIF is 1.44 . The DIFs increase with braking effect vary from $0 \%$ to $27.18 \%$ and the average increment of the DIFs reach $13.80 \%$ with braking effect.

Fig. 9 shows variation of DIF in term of vertical deflection at $30 \mathrm{~km} / \mathrm{h}$ vehicle speed considering braking, the maximum of DIF is 1.51 . The DIFs increase with braking effect 


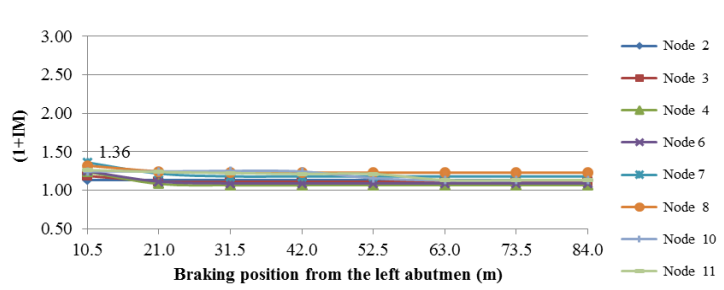

Fig. 7. Variation of DIF in terms of vertical deflections at $10 \mathrm{~km} / \mathrm{h}$ vehicle speed considering braking

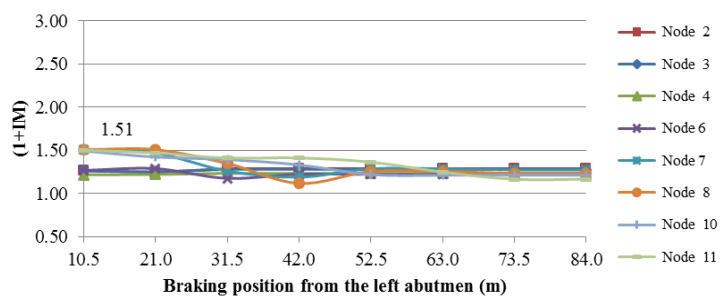

Fig. 9. Variation of DIF in terms of vertical deflections at $30 \mathrm{~km} / \mathrm{h}$ vehicle speed considering braking

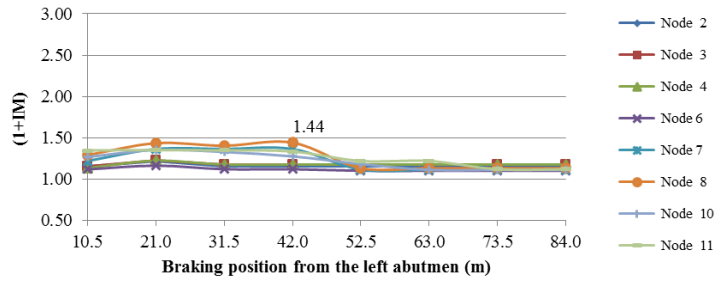

Fig. 8. Variation of DIF in terms of vertical deflections at $20 \mathrm{~km} / \mathrm{h}$ vehicle speed considering braking

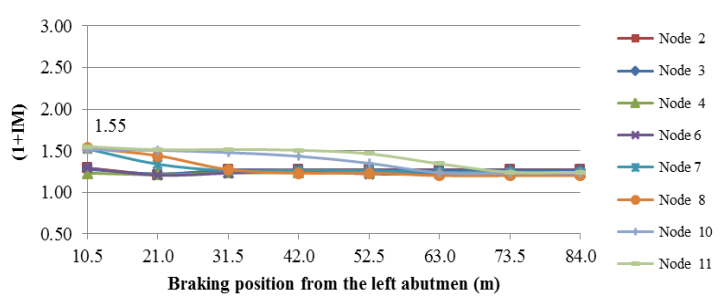

Fig. 10. Variation of DIF in terms of vertical deflections at $40 \mathrm{~km} / \mathrm{h}$ vehicle speed considering braking

vary from $0 \%$ to $28.68 \%$ and the average increment of the DIFs reach $12.27 \%$ with braking effect.

Fig. 10 shows variation of DIF in term of vertical deflection at $40 \mathrm{~km} / \mathrm{h}$ vehicle speed considering braking, the maximum of DIF is 1.55. The DIFs increase with braking effect vary from $0 \%$ to $27.48 \%$ and the average increment of the DIFs reach $13.28 \%$ with braking effect.

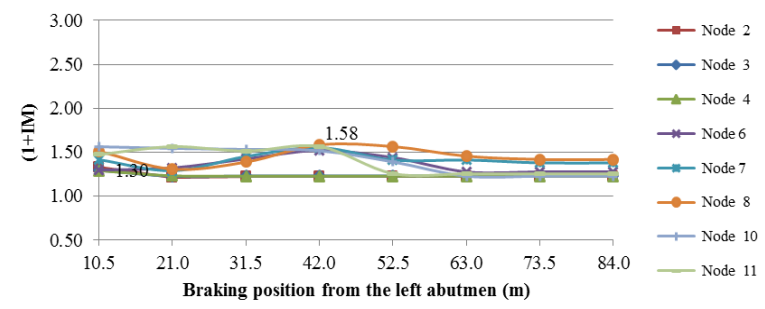

Fig. 11. Variation of DIF in terms of vertical deflections at $50 \mathrm{~km} / \mathrm{h}$ vehicle speed considering braking

Fig. 11 shows variation of DIF in term of vertical deflection at $50 \mathrm{~km} / \mathrm{h}$ vehicle speed considering braking, the maximum of DIF is 1.58 . The DIFs increase with braking effect vary from $0 \%$ to $27.30 \%$ and the average increment of the DIFs is $14.41 \%$ with braking effect. 
In most cases, the DIF increases with the vehicle speed. The maximum value of the average DIF is 1.34 at the vehicle speed of $50 \mathrm{~km} / \mathrm{h}$ with braking effect in term of vertical deflection.

\section{TEST PROCEDURES}

\subsection{Bridge}

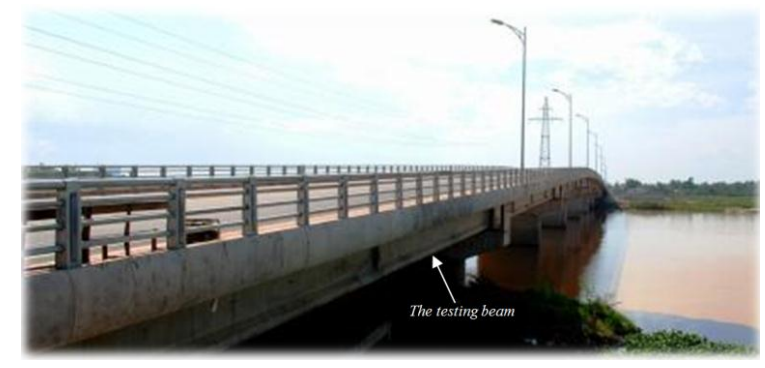

Fig. 12. Picture of Hoa Xuan bridge

Hoa Xuan bridge over the Cam Le river. This seven spans of $42 \mathrm{~m}$, continuous bridge was constructed of pre-stressed concrete girder. Some of the construction details are shown in Fig. 12.

\subsection{Instrumentation}

Instrumentation for measuring deflections was installed at specified locations prior to testing. The vertical deflections were measured, with linear variable displacement transducers (LVDTs), designed to provide displacement measurements. The LVDTs used for the dynamic tests were CDP-50 and CDP-100 gages manufactured by Tokyo Sokki Kenkyujo Co., Ltd. of Japan and shown on Fig. 13. The gages were hang on the under

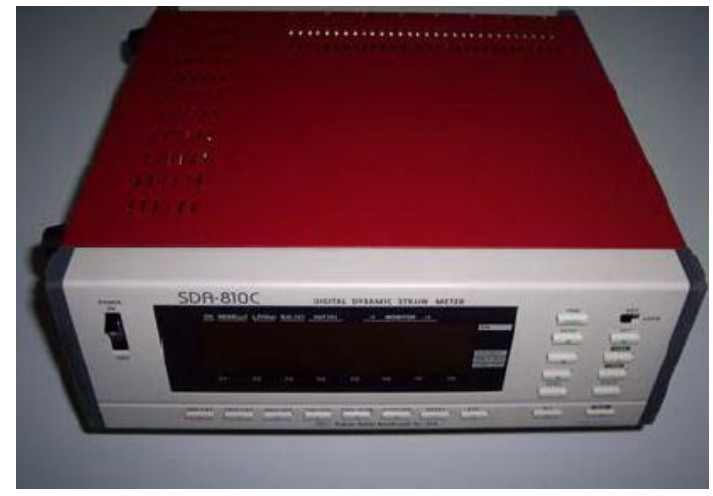

(a) The data record system

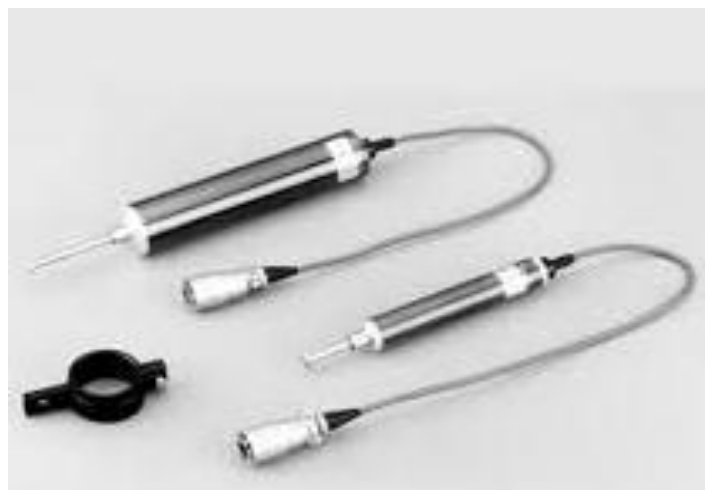

(b) CDP-50 and CDP-100 displacement transducer

Fig. 13. The instruments of testing 
girder (at points 1, 2, 3, 4 as shown on Fig. 14) using a special steel wires developed by the research team. These particular LVDTs have a through-tube construction which allows a spring to be mounted at a fixed height under the core and tube. As the deflection occurs the spring will hold the tube at a fixed elevation and allow the core to move with the structure and along the tube. As the core moves through the tube, the voltage output changes. This voltage change can then be read with the data record system and converted to deflection.

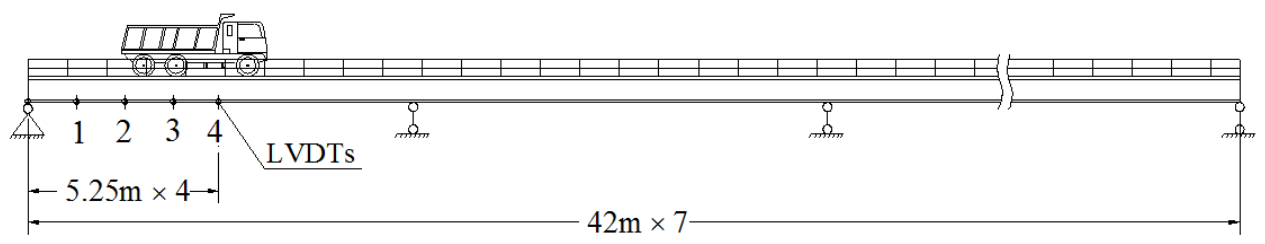

Fig. 14. Hanging points of LVDTs on the Hoa Xuan bridge

\subsection{Vehicle Testing}

The test vehicle for the Hoa Xuan bridge is an ASIA dumper truck with three-axle (Fig. 15) and the vehicle weight is $140600(\mathrm{~kg})$ with leaf spring suspension on the steering axle and the tandem rear axle. The test vehicles were driven over the bridges at speeds of $10 \mathrm{~km} / \mathrm{h}, 20 \mathrm{~km} / \mathrm{h}, 30 \mathrm{~km} / \mathrm{h}$ and $40 \mathrm{~km} / \mathrm{h}$, braking at positions $1,2,3,4$ of the first span (Fig. 14).

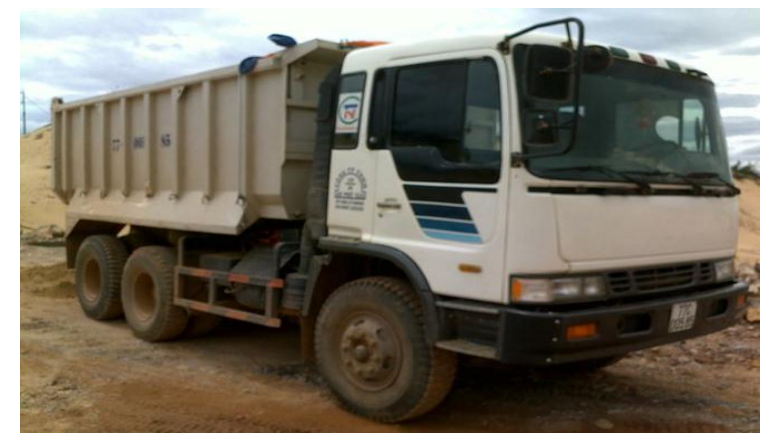

Fig. 15. The ASIA dumper truck

\subsection{Results and Discussions}

The experimental results of DIFs at points 1, 2, 3, 4 on the Hoa Xuan bridge, with the velocity at sudden braking time ranging from $10 \mathrm{~km} / \mathrm{h}$ to $40 \mathrm{~km} / \mathrm{h}$ are illustrated in Fig. 14. The larger velocity has not been tested because safe conditions were not allowed. The vehicle driving is repeated at least 03 times at each point. The experimental results is compared with FEM result (Figs. 16-17, Tabs. 1-2). 


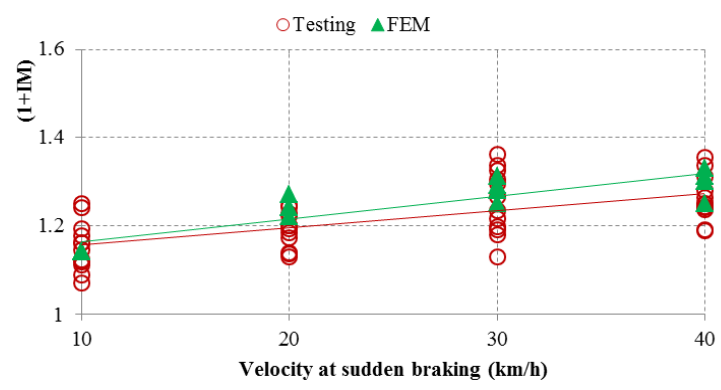

(a) DIF versus velocity, sudden braking at point 1

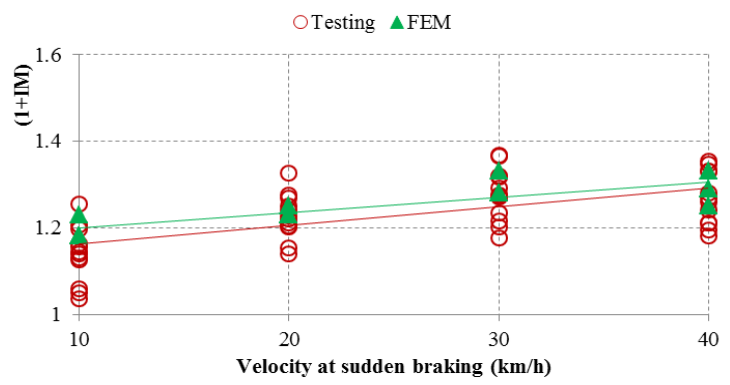

(c) DIF versus velocity, sudden braking at point 3

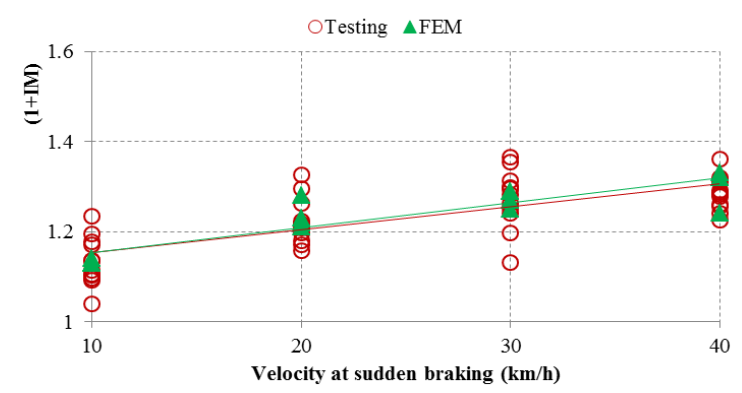

(b) DIF versus velocity, sudden braking at point 2

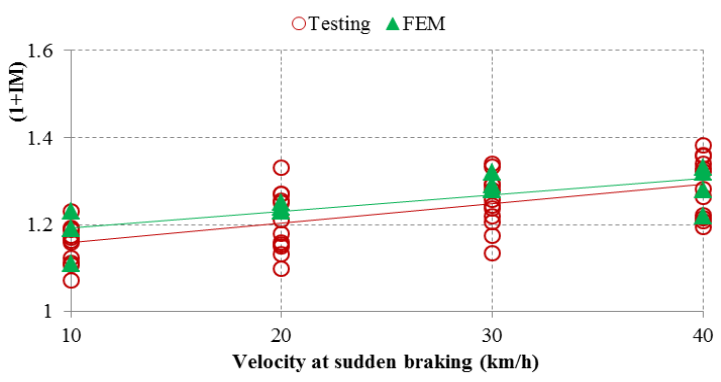

(d) DIF versus velocity, sudden braking at point 4

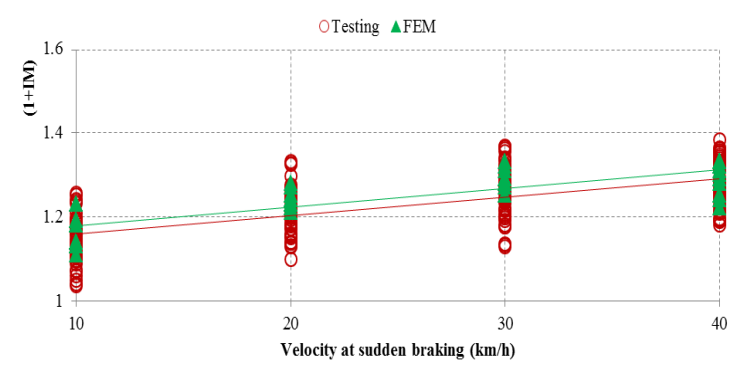

(e) DIF versus velocity, sudden braking at all points $1,2,3,4$

Fig. 16. DIF versus velocity at sudden braking

Through experimental results and FEM analysis of DIFs at positions 1, 2, 3, 4 of the Hoa Xuan bridge are shown on Fig. 16-17, the authors have following comments:

- The uptrend and the downtrend of DIFs are found in experimental investigation and FEM analysis is similarity.

- In velocity range of $10-40 \mathrm{~km} / \mathrm{h}$, the DIF increases with an increase in velocity at sudden braking, the variation of DIF with velocity at sudden braking are shown on Figs. 16(a)-16(e).

- In the limits of velocity, the DIF decreases with increasing the distance from the bearing location, the variation of DIF with braking positions are shown on Figs. 17(a)17(e). 


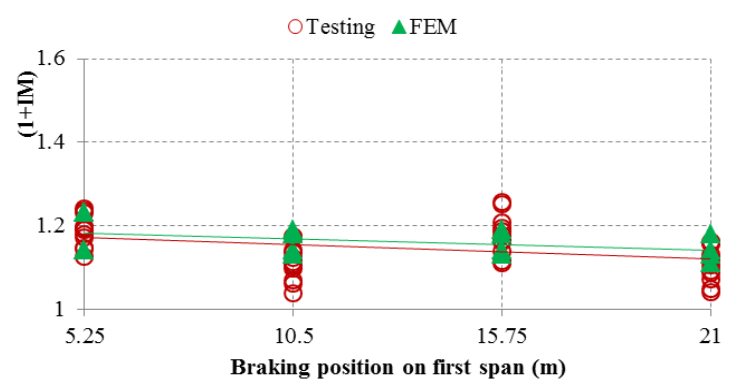

(a) DIF versus braking position, $\mathrm{V}=10 \mathrm{~km} / \mathrm{h}$

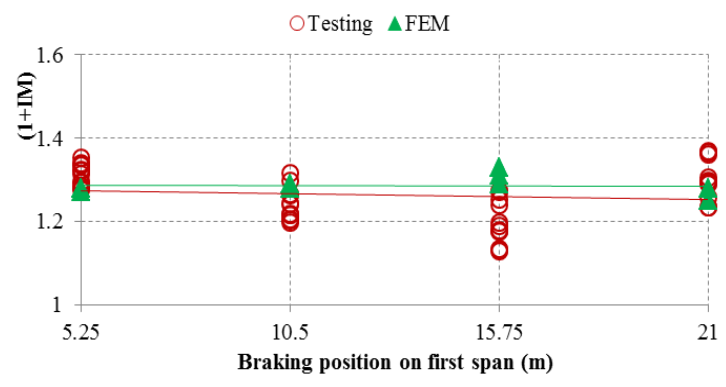

(c) DIF versus braking position, $\mathrm{V}=30 \mathrm{~km} / \mathrm{h}$

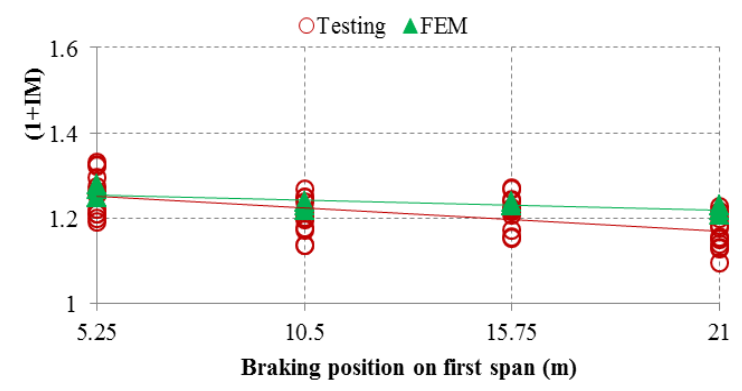

(b) DIF versus braking position, $\mathrm{V}=20 \mathrm{~km} / \mathrm{h}$

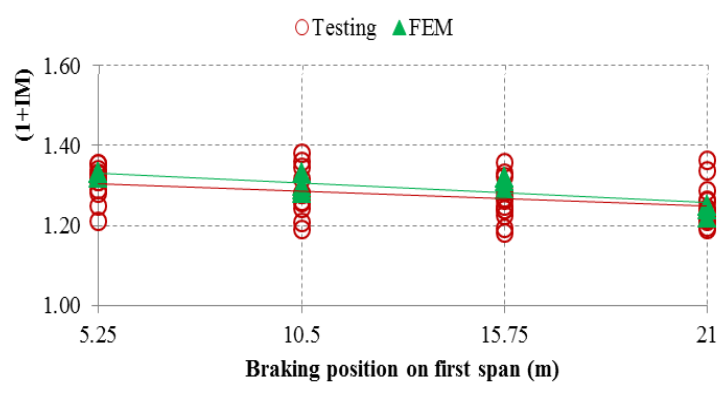

(d) DIF versus braking position, $\mathrm{V}=40 \mathrm{~km} / \mathrm{h}$

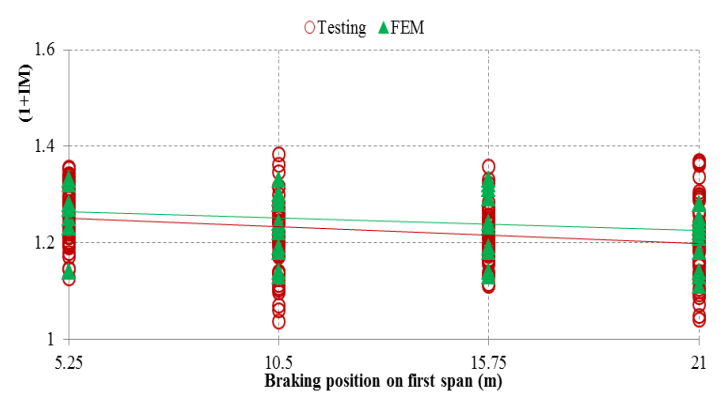

(e) DIF versus braking position, $\mathrm{V}=10-40 \mathrm{~km} / \mathrm{h}$

Fig. 17. DIF versus braking position

- In velocity range of $10-40 \mathrm{~km} / \mathrm{h}$, the maximum deviation between FEM average results and testing average results of DIF about $2.23 \%$ (shown in Tab. 2). Almost all cases, the DIF of FEM results are larger than those obtained from the testings on field. So the FEM result is relatively accurate and reliable.

- In velocity range of $10-40 \mathrm{~km} / \mathrm{h}$, the maximum average of DIF results by FEM is 1.294 and by testing is 1.276 (at speed of $40 \mathrm{~km} / \mathrm{h}$ ) 
Table 1. The DIF values of testing on field

\begin{tabular}{|c|c|c|c|c|c|c|c|c|c|c|c|c|c|c|c|}
\hline \multirow{3}{*}{$\begin{array}{l}\text { Velocity } \\
\text { at sudden } \\
\text { braking } \\
(\mathrm{km} / \mathrm{h})\end{array}$} & \multirow{3}{*}{$\begin{array}{l}\text { Braking } \\
\text { positions } \\
\text { on first } \\
\text { span }(\mathrm{m})\end{array}$} & \multicolumn{12}{|c|}{$(1+\mathrm{IM})$ or DIF } & \multirow{3}{*}{\multicolumn{2}{|c|}{$\begin{array}{c}\text { Average } \\
\text { value } \\
\text { of } \\
\text { DIFs }\end{array}$}} \\
\hline & & \multicolumn{3}{|c|}{ Point 1} & \multicolumn{3}{|c|}{ Point 2} & \multicolumn{3}{|c|}{ Point 3} & \multicolumn{3}{|c|}{ Point 4} & & \\
\hline & & 1 st & 2nd & 3 rd & 1st & 2nd & 3 rd & 1st & 2nd & $3 r d$ & 1st & 2nd & $3 \mathrm{rd}$ & & \\
\hline \multirow{4}{*}{10} & 5.25 & 1.198 & 1.145 & 1.125 & 1.146 & 1.241 & 1.178 & 1.231 & 1.19 & 1.193 & 1.171 & 1.235 & 1.194 & 1.187 & \multirow{4}{*}{1.146} \\
\hline & 10.5 & 1.06 & 1.14 & 1.037 & 1.123 & 1.07 & 1.112 & 1.175 & 1.171 & 1.107 & 1.103 & 1.136 & 1.096 & 1.111 & \\
\hline & 15.75 & 1.255 & 1.163 & 1.207 & 1.161 & 1.25 & 1.194 & 1.111 & 1.164 & 1.187 & 1.177 & $\mid 1.137$ & 1.115 & 1.177 & \\
\hline & 21 & 1.156 & 1.049 & 1.131 & 1.162 & 1.119 & 1.088 & 1.123 & 1.072 & 1.159 & 1.105 & 1.04 & 1.093 & 1.108 & \\
\hline \multirow{4}{*}{20} & 5.25 & 1.325 & 1.275 & 1.212 & 1.223 & 1.193 & 1.201 & 1.211 & 1.255 & 1.331 & 1.263 & 1.296 & 1.327 & 1.259 & \multirow{4}{*}{1.211} \\
\hline & 10.5 & 1.24 & 1.251 & 1.204 & 1.138 & 1.2 & 1.137 & 1.27 & 1.178 & 1.25 & 1.197 & 1.172 & 1.218 & 1.205 & \\
\hline & 15.75 & 1.269 & 1.22 & 1.226 & 1.245 & 1.172 & 1.243 & 1.154 & 1.271 & 1.158 & 1.223 & $\mid 1.217$ & 1.209 & 1.217 & \\
\hline & 21 & 1.153 & 1.14 & 1.201 & 1.129 & 1.185 & 1.227 & 1.131 & 1.151 & 1.098 & 1.157 & 1.217 & 1.18 & 1.164 & \\
\hline \multirow{4}{*}{30} & 5.25 & 1.275 & 1.291 & 1.32 & 1.337 & 1.324 & 1.296 & 1.333 & 1.34 & 1.28 & 1.283 & 1.354 & 1.313 & 1.312 & \multirow{4}{*}{1.263} \\
\hline & 10.5 & 1.202 & 1.215 & 1.316 & 1.266 & 1.198 & 1.216 & 1.243 & 1.219 & 1.205 & 1.241 & 1.262 & 1.298 & 1.240 & \\
\hline & 15.75 & 1.176 & 1.27 & 1.274 & 1.129 & 1.19 & 1.179 & 1.135 & 1.175 & 1.238 & 1.197 & 1.132 & 1.253 & 1.196 & \\
\hline & 21 & 1.233 & 1.366 & 1.368 & 1.36 & 1.234 & 1.305 & 1.293 & 1.257 & 1.29 & 1.298 & 1.366 & 1.296 & 1.306 & \\
\hline \multirow{4}{*}{40} & 5.25 & 1.211 & 1.33 & 1.353 & 1.353 & 1.31 & 1.25 & 1.341 & 1.328 & 1.282 & 1.311 & 1.32 & 1.291 & 1.307 & \multirow{4}{*}{1.276} \\
\hline & 10.5 & 1.28 & 1.26 & 1.346 & 1.244 & 1.279 & 1.189 & 1.382 & 1.361 & 1.209 & 1.315 & 1.257 & 1.279 & 1.283 & \\
\hline & 15.75 & 1.268 & 1.18 & 1.33 & 1.24 & 1.263 & 1.249 & 1.357 & 1.322 & 1.194 & 1.283 & 1.241 & 1.226 & 1.263 & \\
\hline & 21 & 1.211 & 1.242 & 1.195 & 1.236 & 1.19 & 1.336 & 1.222 & 1.264 & 1.214 & 1.286 & 1.362 & 1.261 & 1.252 & \\
\hline
\end{tabular}

Table 2. The DIF values for FEM analysis

\begin{tabular}{|c|c|c|c|c|c|c|c|c|}
\hline \multirow{2}{*}{$\begin{array}{l}\text { Velocity } \\
\text { at sudden } \\
\text { braking } \\
(\mathrm{km} / \mathrm{h})\end{array}$} & \multirow{2}{*}{$\begin{array}{c}\text { Braking } \\
\text { positions } \\
\text { on first } \\
\text { span }(\mathrm{m})\end{array}$} & \multicolumn{4}{|c|}{$(1+\mathrm{IM})$ or DIF } & \multirow{2}{*}{\multicolumn{2}{|c|}{$\begin{array}{c}\text { Average } \\
\text { value } \\
\text { of } \\
\text { DIFs }\end{array}$}} & \multirow{2}{*}{$\begin{array}{c}\text { Difference } \\
\text { between FEM } \\
\text { and } \\
\text { Testing results }\end{array}$} \\
\hline & & $\begin{array}{c}\text { Point } \\
1\end{array}$ & $\begin{array}{c}\text { Point } \\
2\end{array}$ & $\begin{array}{c}\text { Point } \\
3\end{array}$ & $\begin{array}{c}\text { Point } \\
4\end{array}$ & & & \\
\hline \multirow{4}{*}{10} & 5.25 & 1.14 & 1.14 & 1.23 & 1.23 & 1.185 & \multirow{4}{*}{1.161} & \multirow{4}{*}{$1.31 \%$} \\
\hline & 10.5 & 1.14 & 1.13 & 1.18 & 1.19 & 1.160 & & \\
\hline & 15.75 & 1.14 & 1.13 & 1.18 & 1.19 & 1.160 & & \\
\hline & 21 & 1.14 & 1.13 & 1.18 & 1.11 & 1.140 & & \\
\hline \multirow{4}{*}{20} & 5.25 & 1.27 & 1.28 & 1.25 & 1.25 & 1.263 & \multirow{4}{*}{1.238} & \multirow{4}{*}{$2.23 \%$} \\
\hline & 10.5 & 1.24 & 1.22 & 1.23 & 1.24 & 1.233 & & \\
\hline & 15.75 & 1.24 & 1.23 & 1.23 & 1.23 & 1.233 & & \\
\hline & 21 & 1.22 & 1.21 & 1.23 & 1.23 & 1.223 & & \\
\hline \multirow{4}{*}{30} & 5.25 & 1.28 & 1.27 & 1.28 & 1.29 & 1.280 & \multirow{4}{*}{1.286} & \multirow{4}{*}{$1.82 \%$} \\
\hline & 10.5 & 1.29 & 1.29 & 1.28 & 1.28 & 1.285 & & \\
\hline & 15.75 & 1.31 & 1.29 & 1.33 & 1.32 & 1.313 & & \\
\hline & 21 & 1.25 & 1.25 & 1.28 & 1.28 & 1.265 & & \\
\hline \multirow{4}{*}{40} & 5.25 & 1.33 & 1.32 & 1.33 & 1.33 & 1.328 & \multirow{4}{*}{1.294} & \multirow{4}{*}{$1.41 \%$} \\
\hline & 10.5 & 1.3 & 1.33 & 1.29 & 1.28 & 1.300 & & \\
\hline & 15.75 & 1.31 & 1.32 & 1.29 & 1.32 & 1.310 & & \\
\hline & 21 & 1.25 & 1.24 & 1.25 & 1.22 & 1.240 & & \\
\hline
\end{tabular}




\section{CONCLUSIONS}

This study introduces the results of research on dynamic interaction model between a three-axle vehicle and a continuous concrete girder bridge considering braking effects. The FEM has been applied to vibration analysis of the Hoa Xuan bridge and the FEM results were verified by the experiments. In this paper, the FEM results show that the DIF can be larger than 1.34 for continuous concrete girder bridge and about $30 \%$ for maximum increment of DIF with illustratable braking effects. In addition, the DIFs are investigated on both FEM analysis and experiment study on the Hoa Xuan bridge with velocity within the range of $10-40 \mathrm{~km} / \mathrm{h}$. The DIF increases with an increase in velocity at sudden braking, the DIF decreases with an increase of the distance from the bearing support location, the maximum average of DIF results by FEM is 1.294 and by testing is 1.276 (at speed of $40 \mathrm{~km} / \mathrm{h}$ ). Accordingly, the authors recommend that in bridge design, engineers should take into account the dynamic interaction caused by the vehicle moving on bridge and the sudden braking.

\section{REFERENCES}

[1] L. Fryba. Quasi-static distribution of braking and starting forces in rails and bridge. Railway International, 5, (11), (1974), pp. 698-716.

[2] H. Kishan and R. W. Traill-Nash. A modal method of calculation of highway bridge response with vehicle braking. Civil engineering Transactions, Institution of Engineers, 18, (1), (1977), pp. 44-50.

[3] R. K. Gupta and R. Traill-Nash. Bridge dynamic loading due to road surface irregularities and braking of vehicle. Earthquake Engineering E Structural Dynamics, 8, (2), (1980), pp. 8396. doi:10.1002/eqe.4290080202.

[4] N. L. Mulcahy. Bridge response with tractor-trailer vehicle loading. Earthquake Engineering $\mathcal{E}$ Structural Dynamics, 11, (5), (1983), pp. 649-665. doi:10.1002/eqe.4290110505.

[5] Y. B. Yang and Y. S. Wu. A versatile element for analyzing vehicle-bridge interaction response. Engineering Structures, 23, (2001), pp. 452-469. doi:10.1016/s0141-0296(00)00065-1.

[6] H. Haiyan and H. Qiang. Three dimensional modeling and dynamic analysis of four-wheelsteering vehicles. Acta Mechanica Sinica, 19, (1), (2003), pp. 79-88. doi:10.1007/bf02487456.

[7] S. S. Law and X. Q. Zhu. Bridge dynamic responses due to road surface roughness and braking of vehicle. Journal of Sound and Vibration, 282, (3), (2005), pp. 805-830. doi:10.1016/j.jsv.2004.03.032.

[8] S. H. Ju and H. T. Lin. A finite element model of vehicle-bridge interaction considering braking and acceleration. Journal of Sound and Vibration, 303, (1), (2007), pp. 46-57. doi:10.1016/j.jsv.2006.11.034.

[9] A. González, C. Rowley, and E. J. OBrien. A general solution to the identification of moving vehicle forces on a bridge. International Journal for Numerical Methods in Engineering, 75, (3), (2008), pp. 335-354. doi:10.1002/nme.2262.

[10] Z. Zhao and N. Uddin. Field calibrated simulation model to perform bridge safety analyses against emergency braking of trucks. Engineering Structures, 56, (2013), pp. 2253-2262. doi:10.1016/j.engstruct.2013.09.003.

[11] L. Deng, W. He, and Y. Shao. Dynamic impact factors for shear and bending moment of simply supported and continuous concrete girder bridges. Journal of Bridge Engineering, 20, (11), (2015). doi:10.1061/(asce)be.1943-5592.0000744. 
[12] AASHTO. LRFD bridge design specifications. American Association of State Highway and Transportation Officials, Washington, DC, (2012).

[13] W. C. Ray and P. Joseph. Dynamics of structures, Vol. 3. Computers \& Structures, Berkeley, California, (1995).

[14] O. C. Zienkiewicz and R. L. Taylor. The finite element method, Vol. 5. Butterworth-Heinemann, Oxford, (2000).

[15] N. X. Toan. Dynamic interaction between the two-axle vehicle and continuous girder bridge with considering vehicle braking force. Vietnam Journal of Mechanics, 36, (1), (2014), pp. 49-60. doi:10.15625/0866-7136/36/1/2949.

[16] X. N. Toan and V. T. Duc. A finite element model of vehicle-cable stayed bridge interaction considering braking and acceleration. In Proceeding of the 2014 World Congress on Advances in Civil, Environmental, and Materials Research, Busan, Korea, (2014). pp. 806-825.

[17] X. N. Toan and V. T. Duc. Vehicle-cable stayed bridge dynamic interaction considering the vehicle braking effects using the finite element method. In Proceedings of the 16th Asia Pacific Vibration Conference, Hanoi, Vietnam, (2015). pp. 196-203.

[18] X. N. Toan and V. T. Duc. Determination of dynamic impact factor for continuous bridge and cable-stayed bridge due to vehicle braking force with experimental investigation. In Proceedings of the 16th Asia Pacific Vibration Conference, Hanoi, Vietnam, (2015). pp. 260-267.

[19] X.-T. Nguyen, V.-D. Tran, and N.-D. Hoang. A study on the dynamic interaction between three-axle vehicle and continuous girder bridge with consideration of braking effects. Journal of Construction Engineering, 2017, (2017). doi:10.1155/2017/9293239. 